\title{
تأثير تمرينات البيلاتس Pilates على بعض متغيرات التنفس لدي ناشئي كرة القدم تحت 16 سنة
}

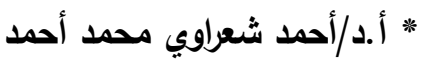

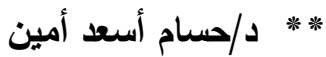

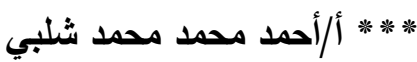

\section{مقدمة البحث}

تعتبر الرياضة فى الأونة الحديثة هي المرآة التي تعكس تقدم ورقى الأمم والثعوب، وتبدأ الخطوة الأولى على طريق التقدم والإصلاح بتطبيق البرامج المختلفة المبنية على أسس علمبة صحيحة منذ سنوات الممارسة المبكرة حتى تلحق الرياضة المصرية بالتطور العالمي الرهيب فى المجال الرياضي والمزود بمعايير جديدة للتفوق، وتعكس الإنجازات الرياضية فى السنوات الأخيرة من هذا القرن الحادي والعشرين مدى الاستفادة من التقام العلمي بتطبيق العلوم المختلفة المرتبطة بالمجال الرياضي فى إعداد الرياضيين للوصول بهم إلى المستويات العالية بدءا من مرحلة النانشئين باعتبارهم الركيزة الأساسية التي يعتمد عليها فى تحقيق الطموحات الرياضية. وتعتبر كرة القدم هي اللعبة الثعبية الأولى والتي يتجه إلى ممارستها العديد بل الغالبية العظمى من شرائح المجتمع باختلاف أعمارهم وتفاوت مستوياتهم الاجتماعية وكذلك كلا الجنسين، لذلك كان

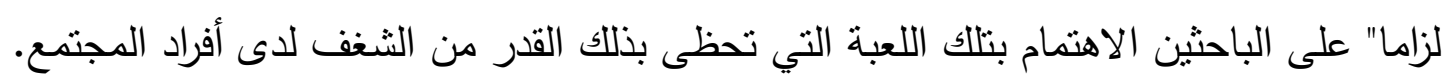
ويشير كلا" من أبو العلا عبد الفتاح (1997) ، عصام عبد الخالق (2005) إلى أن الأساليب الحديثة فى التدريب الرياضي تهدف إلى وصول اللاعب لمستوى الآداء الرياضي الأمنل حيث يعتبر التدريب الرياضي نواه عملية إعداد الرياضي باعتباره العملية البدنية التربوية الخاصة والقائمة على تهيئة الرياضي بدنيا" باستخدام التدريبات البدنية بهدف تطوير مختلف الصفات اللازمة لمواجهة متطلبات النشاط الرياضي الممارس لتحقيق أعلى مسنوى مدكن. (13:1)(7:8) وتعتبر تدريبات البياتس Pilates مجموعة من الحركات البدنية المصممة لنقوية الجسم وتحقيق توازنه، وتصدبها انماط من التنفس فلا يقتصر نتأثثر هذه التذريبات على تحقيق (القوة،

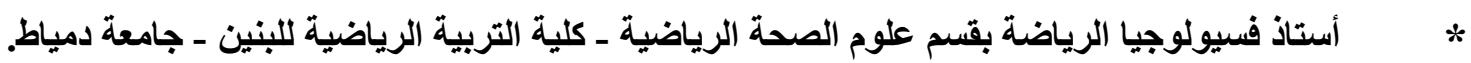

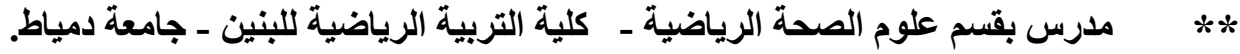

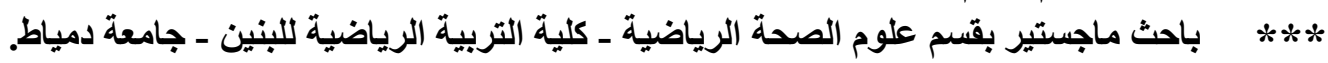


التحمل، المرونة، النوازن) فقط بل يمتد إلى إعادة تأهيل الجسم من جميع النواحي. (24) ويرى دينيس أوستن Denise Austin (2002) أن ممارسة هذه الندريبات تزيد من مستوى طاقة الجسم، وتمنح القدرة على تحرير الجسم من التوتر والضغوط وآلام أسفل الظهر البسيطة، وكذلك تطوير المرونة وتساعد فى الحصول على عضلات قوية بالإضافة إلى تحسين عملية التنفس والدورة

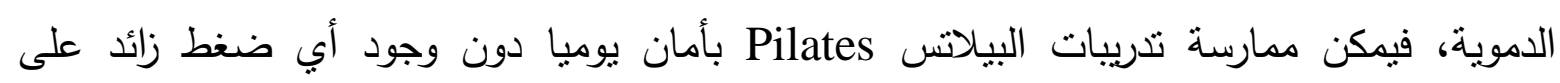

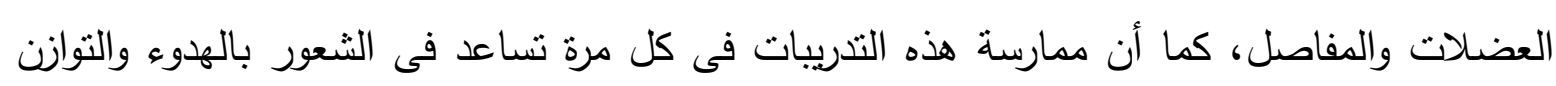

$$
\text { واستعاده الثباب. (26)(15:14)( }
$$

ويرى كل من زينب محمد الإسكندراني(1993)، سعد كمال طه (1994)، عصام عبد الخالق (2005)، أن مبدأ الاستمرارية فى التدريب من الأسس الهامة لتطوير الحالة التنريبية وقدرات الرياضيين وتثبيت ما تم اكتسابه طوال عملية التدريب وبالتالي رفع مستوى الآداء عن طريق رفع كفاءة كلا من القلب والدورة الدموية والرئتين فى نقل الأكسجين إلى العضلات العاملة. $(106: 8)(125: 6)(11: 5)$

ويشير كل من محمد نصر الدين (1998)، ألين وديع فرج (1999)، نعمات عبد الرحمن

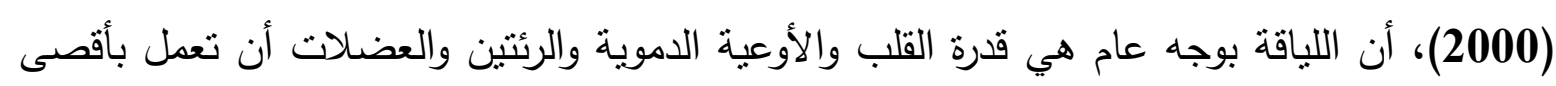
كفاءة، كما أنها القدرة على القيام بنشاط ما بأقصى كفاءة دون الثعور بالتعب، وتؤدى التدريبات الهوائية إلى رفع مستوى اللياقة للفرد، والمحافظة على توازن ومرونة المفاصل وقوة العضلات، كما أنها تزيد من مستوى الطاقة، وتبدد التعب الذى يشعر به الفرد وتتطلب التدريبات الهوائية كميات كبيرة من الأكسجين لفترات طويلة بحيث تدفع الجسم إلى تحسين الأجهزة المسئولة عن نقل وتوصيل الأكسجين للعضلات العاملة وبالتالي نزداد كفاءة وقدرة تحمل القلب والأوعية الدموية والرئتين وتعرف هذه

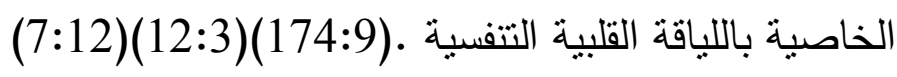

وترى ألين وديع فرج (1999)، أن مصطلح اللياقة القلبية التتفسية يعكس الرؤية الواضحة المبنية على تأثثر التدريب إذ يستخدم هذا المصطلح للإثارة إلى عمليات أخذ الأكسجين ونقله واستهلاكه، وتتحسن هذه العمليات بالتدريب ونظرا لأن التدريب له تأثنر على العضلات ذاتها وقدرتها 
على القيام بإنتاج الطاقة المؤكسة أو الطاقة الهوائية، لذلك فإن العضلات تكون هي الهذف التدريبي.(71:3)

ويذكر أبو العلا عبد الفتاح، أحمد نصر الدين (2003)، أن اللياقة القلبية التتفية هي قدرة الجهازين الدوري والتتفسي على توجيه الأكسجين إلى العضلات العاملة لاستهلاكه أثناء العمل البدني الذي يؤدى لمدة طويلة. (25:2) وتوجد ثلاث أجهزة رئيسية مسئولة عن اللياقة القلبية التتفسية هي الجهاز الدوري والجهاز التنفسي والجهاز العضلي فإذا كان الجهاز التنفسي يقوم بإمداد الجهاز الدوري بكميات كبية من الأكسجين لكى ينقلها إلى العضلات فإن التغيرات الرئيسية تأخذ مكانها فى العضلات المستخدمة فى لئ التدريب ، والتكيفات الثانوية تأخذ مكانها فى الجهاز الدوري والتتفسي والجهاز العصبي والغدد الصماء وأنسجة أخرى ولكن من غير الممكن تحسين وظائف الأعضاء الداخلية منل القلب والرئتين بدون

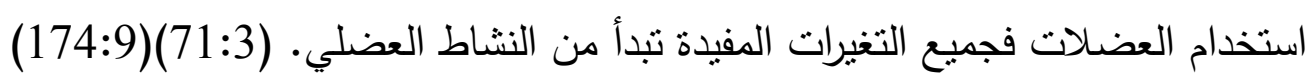
وتعد القدرة الهوائية أفضل مؤشر للياقة القلبية التتفسية وهي قدرة الفرد على استهلاك أكبر كمية من الأكسجين أثثاء بذل أقصى جهذ بدنى ممكن. (173:9) مشكلة البحث

تعتبر اللياقة القلبية التتفية من أهم القواعد التي بمكن أن تبنى عليها إمكانية ممارسة النشاط الرياضي والتي تؤثر بشكل كبير فى تحسين مستوى الآداء، كما أن اكتسابها يعد من أهم الأهداف التي لتئي تسعى برامج التدريب الرياضي إلى تحقيقها. ومن خلد العرض السابق وإطلاع الباحثون على الرراجع والدراسات السابقة العربية والأجنبية وجد الباحثون أن المراجع والدراسات تطرقت لاستخدام تمرينات البيلاتس فى تتمية عناصر اللياقة

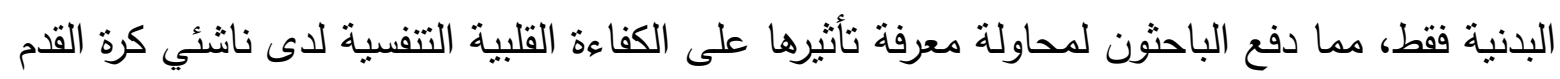
والتي لم تتعرض الدراسات السابقة لهذه المرحلة السنية فى كرة القدم. ومن خـل عمل الباحثون فى مجال تدريب كرة القدم لاحظ الباحثون أن اللاعبين في هذه

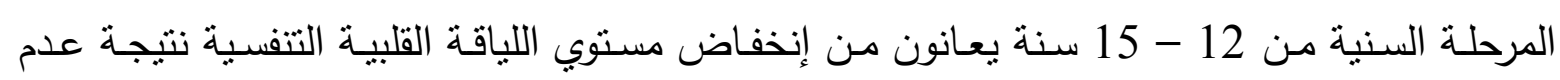
الإهتمام بتطوير هذه الناحية من العملية الندريبية بالإضافة إلي بعض طرق وأساليب التدريب الخاطئة والتي ينتج عنها ظهور التعب والإجهاد في مراحل متقدمة من المنافسات. 
يهدف البحث إلى تصميم برنامج لتدريبات البيلاتس Pilates لمعرفة مدى تأثيره على اللياقة القلبية التتفسية لدى ناشئي كرة القدم في المرحلة العمرية من 13 - 15 سنة. فروض البحث

1. نوجد فروق ذات دلالة إحصائية بين القياس القبلي والبعدي للمجموعة التجريبية التي تستخدم تمرينات البيلاتس فى تحسن اللياقة القلبية التتفسية لصالح القياس البعدي. 2. نوجد فروق ذات دلالة إحصائية فى القياس البعدي بين المجموعة التجريبية والضابطة فى تحسن اللياقة القلبية التنفسية لصالح المجموعة التجريبية. مصطلحات البحث

1. تدريبات البيلاتس: Pilates Exercises "مجموعة من الحركات البدنية المصممة لتطوير مرونة وقوة وتحمل الجسم وتحقيق توازنه

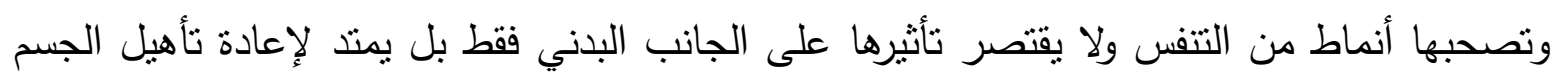
من جميع النواحي". (17:19)

2. اللياقة القلبية التنفسية: Cardio Respiratory Fitness

"قدرة الجهازين الدوري والتتفسي على توجيه الأكسجين إلى العضلات العاملة لاستهلاكه أثناء العمل البدني الذي يؤدى لمدة طويلة". (25:2)

3. القدرة الهوائية: Ability

"أقصى كمية أكسجين يسنطيع الجسم استهاكها خلال وحدة زمنية معينة وهو ما يطلق عليه

الحد الأقصى لاستهلاك الأكسجين" (VO2max). (2: 313) 
الاراسات المرجعية

أولاً: الدراسات المرجعية العربية:

\begin{tabular}{|c|c|c|c|c|c|c|}
\hline أهم النتائج & العينة & المنهج & الهـف & العنوان & اسم الباحث & $\rho$ \\
\hline برنامج تمرينات البيلاتس أثر تأثيرا & 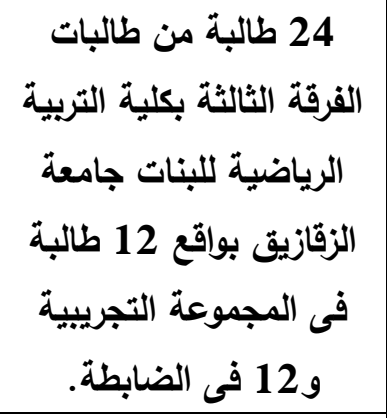 & التجريبي & 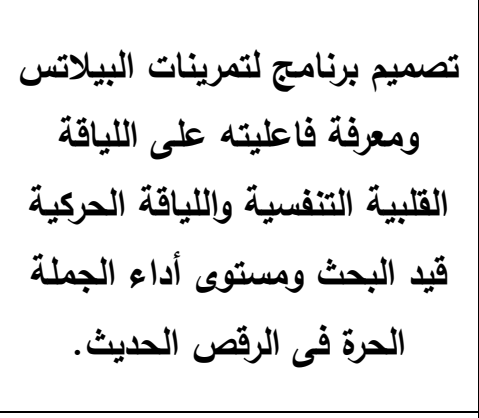 & 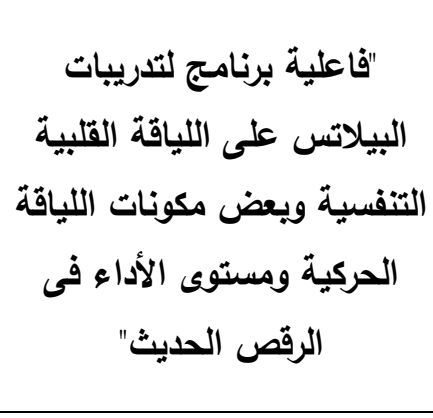 & شالية عادل & 1 \\
\hline 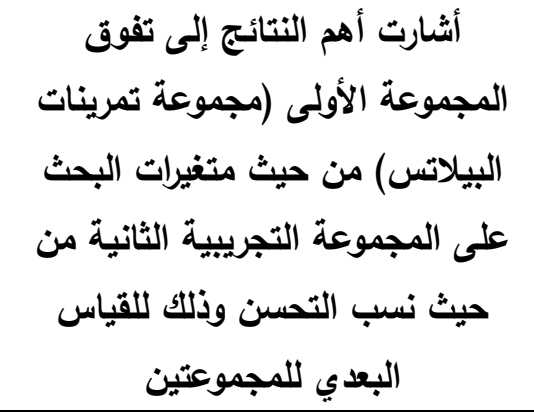 & 16 مجموعتين قوام كلموا إلى 8 مجل 8 تلاميذ & تجريبي & الترينات البيلاتس، على تأثير التتخدام التمرينات & 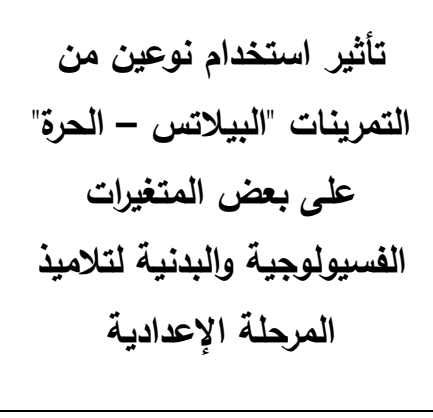 & 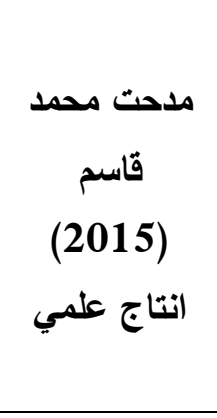 & 2 \\
\hline 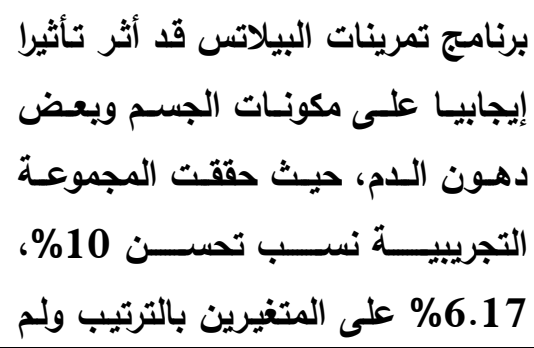 & 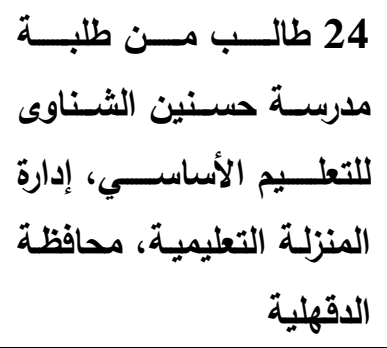 & تجريبي & 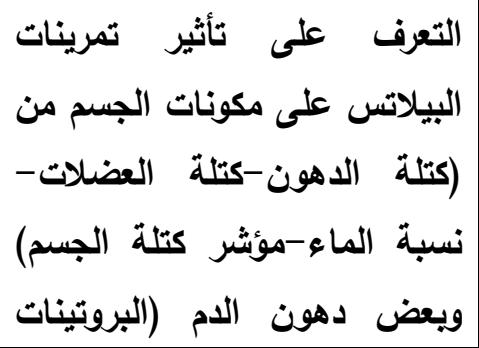 & تمكونات الجسم تمرينات البيلاتس على دهض & الحسينى محمد & 3 \\
\hline
\end{tabular}




\begin{tabular}{|c|c|c|c|c|c|c|c|}
\hline أهم النتائج & العينة & المنهجج & الكهف & \multicolumn{2}{|l|}{ العنوان } & اسم الباحث & r \\
\hline تحقق المجموعة الضابطة تلك النسب & تحقق & & 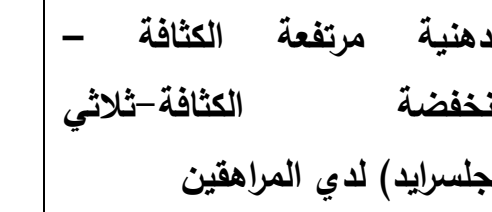 & & & & \\
\hline تحسن اللياقة القلبية لاى السباحين & 24 سباح بإستاد & التجريبيج & تبرف على فاعلية تمرينات & تمرينات البيلاتس على القلبية التنفسية لاثى & فاعليا & الله محمود عبد & 4 \\
\hline \multicolumn{8}{|c|}{ ثانياً: الدراسات المرجعية الأجنبية } \\
\hline أهم النتائج & العينة & المنهج & الكهف & العنوان & & اسم الباحث & 5 \\
\hline العضلية تدريبات البيلاتس القوة & سيدة تم اختيارهم بطريقة العينة على 62 & التجريبي & 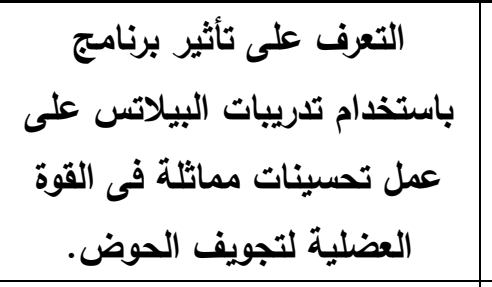 & تجرية عشوائية مقارنة تلخدام تلريبات البيلاتسبن القوة العضلية & (Jan & $\begin{array}{l}\text { جانت سكير وآذ } \\
\text { scher et al., ) } \\
\text { (2009) }\end{array}$ & 5 \\
\hline تمرينات البيلاتس حسنت بالقعل & 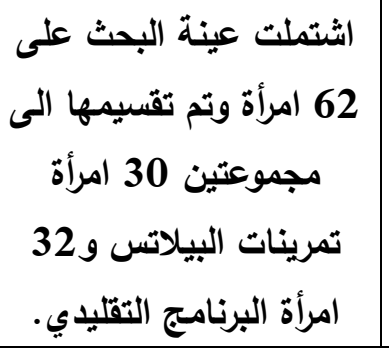 & التجريبي & 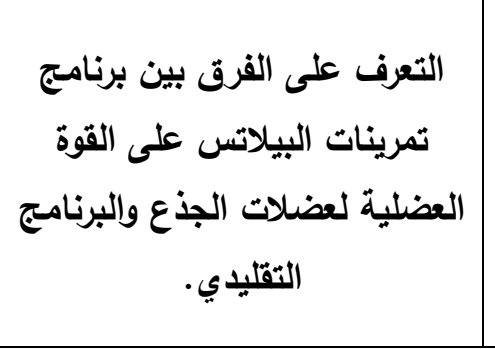 & "دراسة تحليلية مقارنة بين & (Patr & 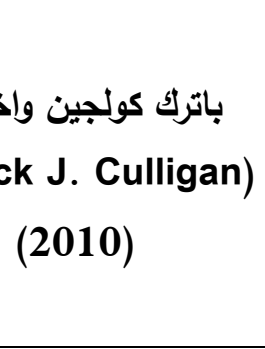 & 6 \\
\hline
\end{tabular}




$$
\text { منهج البحث: إجرات }
$$

استخدم الباحثون المنهج التجريبي باستخدام التصميم التجريبي لمجهوعتين تجريبيتين وذلك

$$
\text { بأجراء القياسات (القبلية -البعدية) }
$$

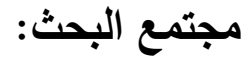

يمثل مجتمع البحث لاعبي كرة القدم تحت 16 سنة بمدينة الكردي مركز منية النصر محافظة

تم إختيار عينة البحث بالطريقة العدية.

•بلغ حجم العينة الكلية للبحث (25) من لاعبي أكاديمية أمجاد الجزيرة لكرة القدم تحت

16 سنة مقسمين إلى مجموعتين كل مجموعة مكونة من (10) لاعبين يتراوح أعمارهم

(13-13 سنة) ومجموعة استطلاعية مكونة من (5) لاعبين.

\begin{tabular}{|c|c|c|c|c|}
\hline \multirow{2}{*}{ البرنامج } & \multicolumn{3}{|c|}{ العينة } & \multirow{2}{*}{ b } \\
\hline & النسبة & العدد & نوع العينة & \\
\hline المقترح & $\% 40.00$ & 10 & المجموعة التجريبية & 1 \\
\hline المتبع & $\% 40.00$ & 10 & المجموعة الضابطة & 2 \\
\hline- & $\% 20.00$ & 5 & المجموعة الاستطلاعية & 3 \\
\hline - & $\% 100$ & 25 & العينة الكلية للبحث & \\
\hline
\end{tabular}

جدول (1)

توصيف عينة البحث.

أ. التحقق من اعتدالية توزيع العينة الكلية للبحث:

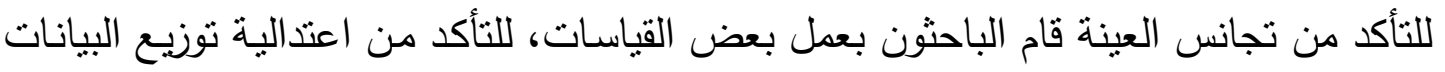

بين أفراد العينة في المتغيرات قيد البحث، كما هو موضح في جدول (2) وشكل (1) 
جدول (2) (2)

المتوسطات الحسابية والوسيط والانحرافات المعيارية ومعاملات الالتواء للعينة الكلية للبحث

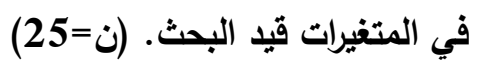

\begin{tabular}{|c|c|c|c|c|c|c|c|}
\hline الالتواء & الانحراف & الوسيط & المتوسط & |وحدة القياس & المتغيرات & & \\
\hline $0.17-$ & 7.21 & 166.50 & 166.10 & 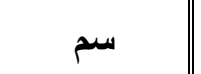 & الطول & & \multirow{3}{*}{ 雨 } \\
\hline 0.18 & 7.79 & 54.00 & 54.47 & كجم & 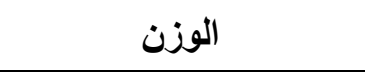 & & \\
\hline 0.00 & 0.79 & 14.00 & 14.00 & 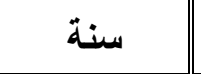 & العمر الزمني (السن) & & \\
\hline $0.68^{-}$ & 5.54 & 39.00 & 37.75 & 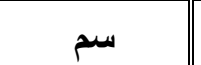 & الوثب العمودي لسيرجينت & القوة القو & \multirow{5}{*}{ 可。 } \\
\hline 0.84 & 4.22 & 5.37 & 6.54 & 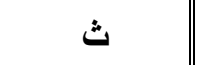 & الدوائر المرقمة & التوافق & \\
\hline $0.85^{-}$ & 6.92 & 3.00 & 1.05 & سم & ثني الجذع من الوقوف & المرونة & \\
\hline 0.81 & 4.42 & 9.55 & 10.74 & $\dot{H}$ & الوقوف على مشط القدم & التوازن & \\
\hline 0.38 & 0.08 & 1.23 & 1.24 & دقيقة & جري 400م & التحمل & \\
\hline 0.33 & 2.74 & 74.00 & 74.30 & |نبضة/دقيقة & معدل النبض & & \multirow{14}{*}{ 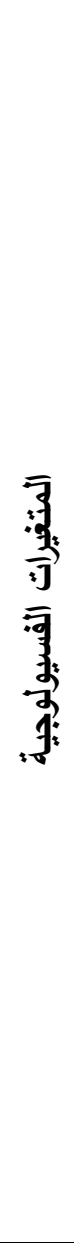 } \\
\hline 0.30 & 2.51 & 122.50 & 122.75 & مم/زئبقي & ضغط انقباضي & & \\
\hline $1.57-$ & 1.53 & 83.50 & 82.70 & مم/زئبقي & ضغط انبساطي & & \\
\hline 0.67 & 15.67 & 64.42 & 67.90 & mg \% & لاكتيك & & \\
\hline 0.70 & 0.54 & 2.93 & 3.05 & لتر & IVC & & \\
\hline 0.59 & 0.63 & 2.42 & 2.54 & 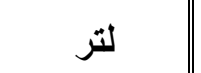 & FVC & & \\
\hline 0.78 & 0.56 & 2.32 & 2.46 & لتر & FEV1 & & \\
\hline $1.50^{-}$ & 7.10 & 98.00 & 94.45 & $\%$ & FEV1/FVC & & \\
\hline $0.81-$ & 7.62 & 79.00 & 76.95 & $\%$ & FEV1/VC & & \\
\hline $0.57-$ & 1.27 & 4.86 & 4.62 & لتر & PEF & & \\
\hline $0.77-$ & 1.59 & 4.39 & 3.99 & لتر/ثانية & MEF75 & & \\
\hline $0.63-$ & 0.99 & 4.05 & 3.84 & لتر/ثانية & MAF50 & & \\
\hline 0.17 & 0.89 & 2.35 & 2.40 & لتر/ثانية & MAF25 & & \\
\hline 0.00 & 0.03 & 3.86 & 3.86 & لتر / دقيقة & 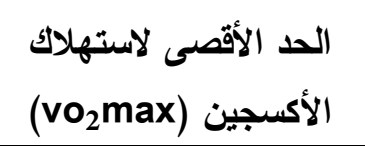 & & \\
\hline
\end{tabular}


يتضح من جدول(2)، أن قيم معاملات الالتواء انحصرت ما بين (-3) و (+3) مما يدل على أن قياسات العينة الكلية للبحث في المتغيرات قيد البحث قد وقعت تحت المنحنى الاعتدالي وهذا يدل على تجانس أفراد عينة البحث الكلية في هذه المتغيرات. ب. تكافؤ مجموعتي البحث: قام الباحثون بإجراء التكافؤ بين (المجموعة التجريبية والمجموعة الضابطة) فى ضوء المتغيرات قبد البحث والتي قد تؤثر على البحث ويوضح جدول (3) تكافؤ المجموعتين في المتغيرات قيد البحث. جدول (3)

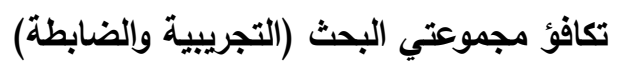
في الاختبارات قيد البحث. (ن1=2=2010

\begin{tabular}{|c|c|c|c|c|c|c|c|c|}
\hline \multirow{2}{*}{ قيمة } & \multicolumn{2}{|c|}{ المجموعة الضابطة } & \multicolumn{2}{|c|}{ المجموعة التجريبية } & \multirow[b]{2}{*}{ وحدة } & \multirow[b]{2}{*}{ المتغيرات } & & \\
\hline & 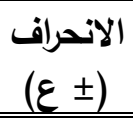 & المتوسط & 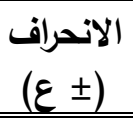 & $\begin{array}{c}\text { المتوسطن) } \\
\text { (سنَ) }\end{array}$ & & & & \\
\hline 0.35 & 3.94 & 38.20 & 6.99 & $\mathbf{3 7 . 3 0}$ & 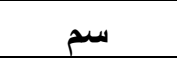 & الوثب العمودي لسيرجينت & القوة & \multirow{5}{*}{ 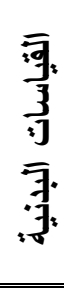 } \\
\hline 0.78 & 1.26 & 5.80 & 5.89 & 7.28 & $\dot{\Xi}$ & الدوائر المرقمة & التوافق & \\
\hline 0.28 & 8.10 & 1.50 & 5.91 & 0.60 & سم & ثني الجذع من الوقوف & المرونة & \\
\hline 0.77 & 4.25 & 9.97 & 4.67 & 11.51 & $\dot{H}$ & الوقوف على مشط القدم & التوازن & \\
\hline 0.65 & 0.10 & 1.25 & 0.06 & 1.22 & دقيقة & جري 400م & التحمل & \\
\hline 1.15 & 3.02 & 75.00 & 2.37 & 73.60 & نبضة|دقيقة & معدل النبض & & \multirow{14}{*}{ 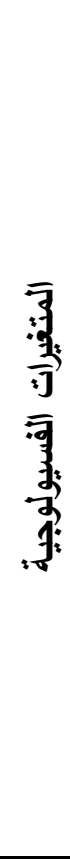 } \\
\hline 1.17 & 2.92 & 122.10 & 1.96 & 123.40 & مم/زئبقي & ضغط انقباضي & & \\
\hline 0.29 & 1.65 & 82.60 & 1.48 & 82.80 & مم/زئبقي & ضغط انبساطي & & \\
\hline 1.09 & 12.42 & 64.09 & 18.22 & 71.72 & $\mathrm{mg} \%$ & لاكتيك & & \\
\hline 0.18 & 0.61 & 3.03 & 0.50 & 3.08 & لتر & IVC & & \\
\hline 0.31 & 0.50 & 2.59 & 0.77 & 2.50 & لتز & FVC & & \\
\hline 0.52 & 0.60 & 2.39 & 0.53 & 2.53 & لتز & FEV1 & & \\
\hline 1.53 & 9.29 & 92.10 & 2.82 & 96.80 & $\%$ & FEV1/FVC & & \\
\hline 0.49 & 8.08 & 77.80 & 7.46 & 76.10 & $\%$ & FEV1/VC & & \\
\hline 1.13 & 1.66 & 4.30 & 0.64 & 4.94 & لتز & PEF & & \\
\hline 0.41 & 2.08 & 3.84 & 0.97 & 4.14 & لتر/ثانية & MEF 75 & & \\
\hline 1.23 & 1.18 & 3.57 & 0.72 & 4.11 & لتر/ثانية & MAF50 & & \\
\hline 1.64 & 0.93 & 2.09 & 0.76 & 2.71 & لتر/ثانية & MAF25 & & \\
\hline 0.88 & 0.02 & 3.86 & 0.03 & 3.87 & لتر/ دقيقة & 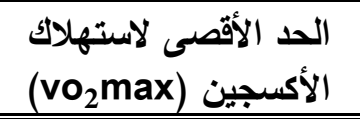 & & \\
\hline
\end{tabular}


يتضح من جدول (3/3) عدم وجود فروق ذات دلالة إحصائية بين القياسات قيد البحث

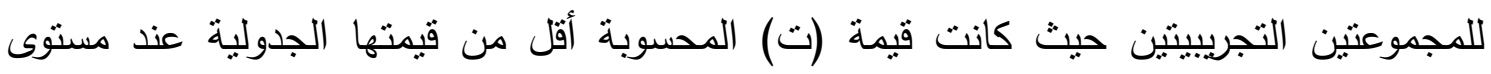

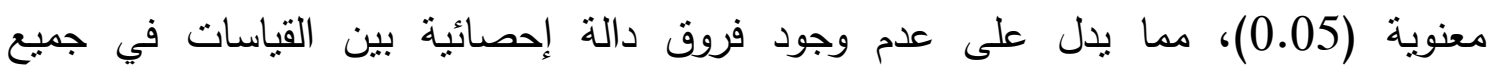
الاختبارات، مما يشير الى تكافؤ المجموعتين في المتغيرات قيد البحث. أدوات جمع البيانات الاختبارات والقياسات البدنية:

قام الباحثون بـالاطلاع على الدراسـات والبحوث والمراجع العلميـة واستطلاع راي الخبراء في مجال علوم الصحة وكرة القدم لتحديد أهم الاختبارات قبد البحث وكانت ما يلي: أ. قياس السعات الرئوية باستخدام جهاز (سبيروستيك Spiro stic). ب. اختبار قياس معدل النبض. الأجهزة والأدوات المستخدمة: جهاز الرستاميتز لقياس الطول والوزن - جهاز الاسبيروستيك -جهاز قياس النبض -كحول ابيض للتطهير بعد أخذ القياس. تصميم البرنامج:

قام الباحثون بدراسة مسحية للكتب والمراجع العربية والأجنيية والبحوث العلمية ومواقع الانترنت التي تتاولت أسس وضع البرامج وتم وضع تصور مبدئي لتمرينات البيلاتس وتصميم استمارة استطلاع رأي الخبراء في أهم التدريبات التي تتتاسب مع عينة البحث مع تحديد مدة تطبيق البرنامج وزمنه وعدد وحداته التدريبيـة الأسبوعية وزمن كل وحدة تدريبية وفي ضوء أراء الخبراء قام البـاحثون بالتعديل والإضافة والإلغاء بما يتتاسب مع هدف عينة البحث.

تقنين البرنامج:

اشتمل البرنامج على (24) وحدة تدريبية بواقع (3) وحدات ندريبية في الأسبوع وذلك لمدة (8) أسـابيع، وهي فترة الإعداد الخاص من الموسم الرياضي، كما تم وضع تمرينات البيلاتس في الجزء الخاص بالإعداد البدني الخاص من الوحدة التدريبية، وقد استغرق زمن كل وحدة تدريبية (90) دقيقة طوال فترة تتفيذ البرنامج، وكان الزمن المحدد لتمرينات البيلاتس في كل وحدة تدريبية يتراوح ما بين 10 
- كنلك راعى الباحثون الأسس التالية فى وضع البرنامج:

أن أنكون التمرينات من النوع السهل البسيط.

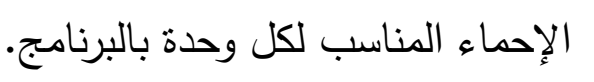

• عدم إجهاد اللاعبين فى التمرينات لفترة طويلة بل يتخلل ذلك فترات راحة ايجابية

$$
\text { • الاهتمام بجميع اللاعبين دون التحيز لأحد منهم. }
$$

حيث تم استخدام تمرينات البيلاتس أثناء فتزة الإعداد الخاص من الوحدة الترريبية مع المجموعة

التجريبية بينما تم استخدام التمرينات النقليدية مع المجموعة الضابطة.

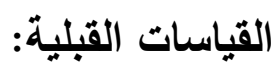

تمت القياسات القبلية لمجموعتي البحث قيد البحث يوم 23-24 / 7 / 2020.

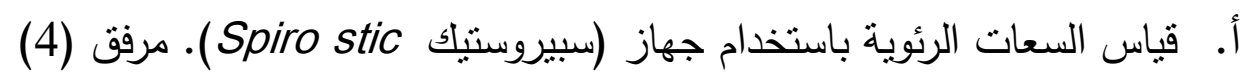

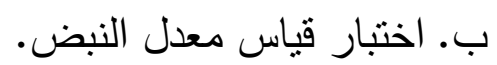

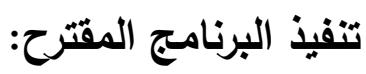

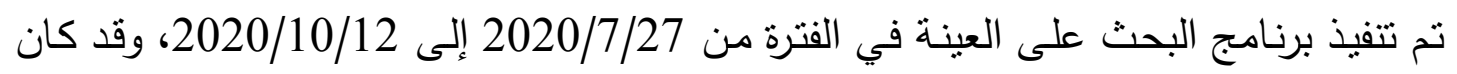

تثنكيل الوحدة التدريبية داخل البرنامج المقترح من خمسة أجزاء وهي:

الإحماء/ الإعداد البني الخاص بتمرينات البيلانس، التمرينات التقليدية / الجزء التصريبي/ الختام.

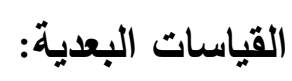

تم إجراء القياس البعدي بعد نهاية الأسبوع (8) من تطبيق البرنامج يوم 14-2020/10/16،

وقد طبقت جميع القياسات على نحو ما نم إجراءه في القياس القبلي للمتغيرات قيد البحث بنفس ترنيب

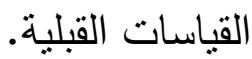


نموذج لوحدة تدريبية من البرنامج التدريبي للمجموعة التجريبية :

التاريخ

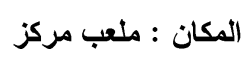

حل التدريب : متوسط

$$
\text { الألسبوع : الأول الأولي من البرنامي }
$$

2020/7/29:

زمن الوحدة التدريبية : 90 ق شباب الكردي

\begin{tabular}{|c|c|c|c|c|c|}
\hline البينة البة & المجموعات & الت التكرار & 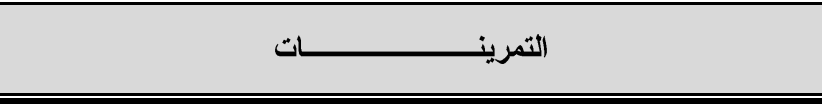 & 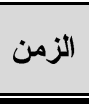 & 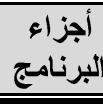 \\
\hline نشطة - ماحة & - & - & 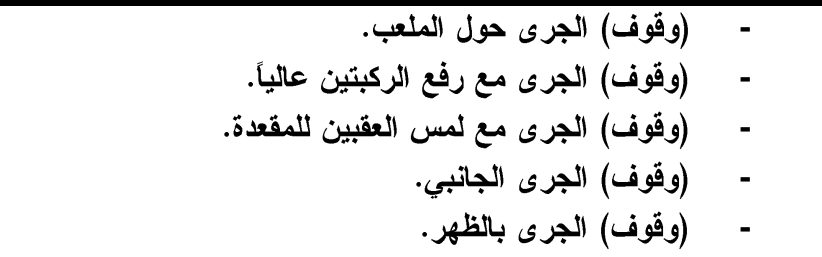 & ق & $\frac{\bar{j}}{3}$ \\
\hline$ث 20$ & 4 & 12 & 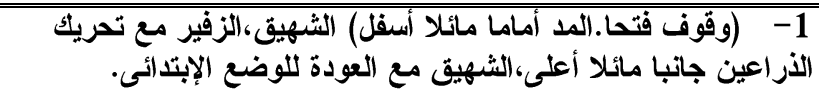 & \multirow{3}{*}{ 15 } & \multirow{3}{*}{ 哥 } \\
\hline$ث 20$ & 4 & 8 & 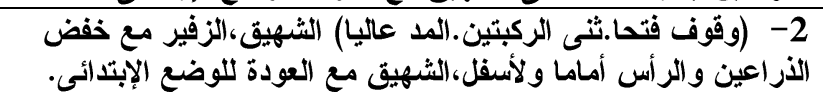 & & \\
\hline ث20 & 2 & 8 & 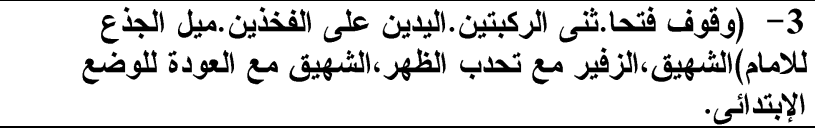 & & \\
\hline ث10 & 2 & 16 & 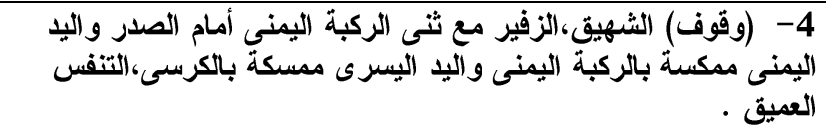 & & \multirow[b]{3}{*}{ 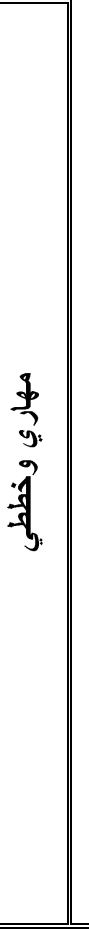 } \\
\hline ث10 & 2 & 16 & 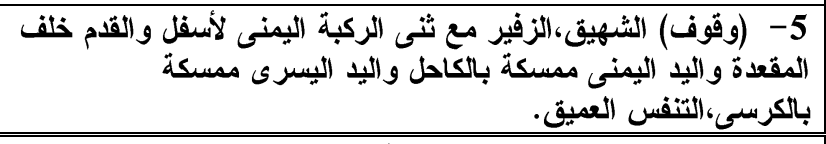 & & \\
\hline 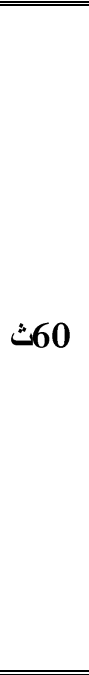 & 4 & 10 & 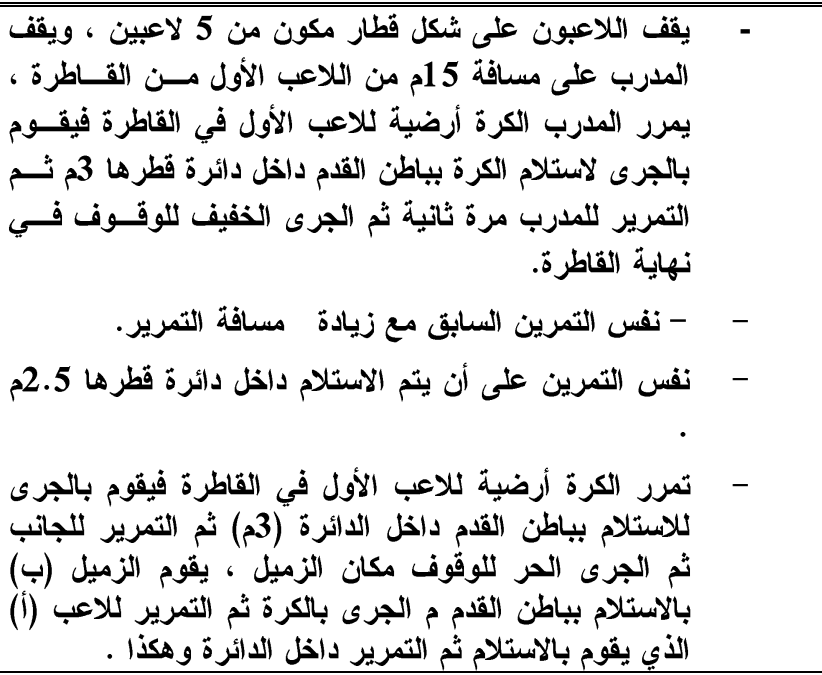 & 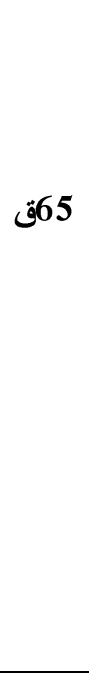 & \\
\hline - & - & - & 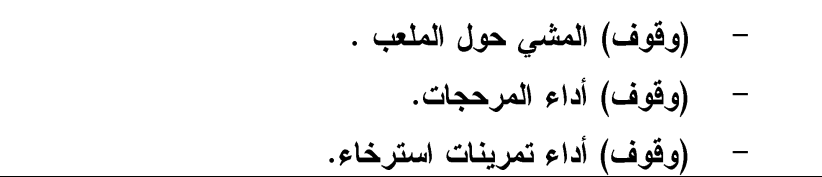 & ق & 率 \\
\hline
\end{tabular}




\section{المعالجات الإحصائية}

استخدم الباحثون في المعالجات الإحصائية للبيانات داخل هذه الدراسة برنامج الحزم الإحصائية للعلوم الاجتماعية (SPSS) الإصدار (23) مستعينًا بالمعاملات التالية: أ. المتوسط الحسابي (Mean)

ب. ب. الوسيط (Median)

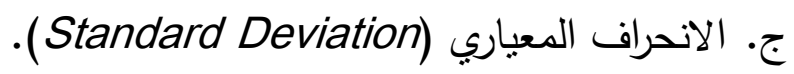
د. (Kurtosis) (الالتواء) هـ اختبار (ت) لعينتين مرتبطتين من البيانات (Paired Sample t-Test). و . اختبار (ت) لعينتين مستقلتين من البيانات (Independent Samples t-Test). ز · حجم التأثير (Effect Size) في حالة اختبار (ت): أ. ائ. مربع ايتا (1/2)

ب. باستخدام (ES) ويفسر طبقا لمحكات كوهين.

Change Ratio ح. نسبة التغيير/ التحسن (معدل التغير) نسبة التحسن = القياس البعدي - القياس القبلي 100 القياس القبلي

عرض ومناقشة النتائج وتفسيرها عرض ومناقشة نتائج الفرض الأول عرض نتائج الفرض الأول:

ينص الفرض الأول على أنه: "توجد فروق ذات دلالة إحصائية بين القياس القبلي والبعدي للمجموعة التجريبية فى تحسن اللياقة القلبية التنفسية لصالح القياس البعدي"؛ وللتحقق من صحة Paired Sample ) الفرض الأول استخدم الباحثون اختبار (ت) لعينتين مرتبطتين من البيانات (tTest)، لدالة الفروق بين متوسط الدرجات في القياس القبلي والقياس البعدي (للمجموعة التجريبية) في المتغيرات (قيد البحث)، كما تم حساب حجم التأثثر (Effect Size) باستخدام مربع ايتا (ض) في 
حالـة اختبـار (ت)، كمـا تـم حسـاب حجم التأثثر باستخدام (ES) ويفسـر طبقـا لمحكـات لكوهين، بالإضافة إلى نسبة التغيير/ التحسن (Change Ratio)، كما في الجداول والاشكال التالية.

جدول (5)

دلالة الفروق بين القياس القبلي والقياس البعدي (للمجموعة التجريبية) في المتغيرات

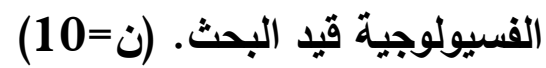

\begin{tabular}{|c|c|c|c|c|c|c|c|c|}
\hline \multicolumn{2}{|c|}{ حجم التأثير } & \multirow{2}{*}{ قيمة } & \multicolumn{2}{|c|}{ القياس البعدي } & \multicolumn{2}{|c|}{ القياس القبلي } & \multirow{2}{*}{ وحدة القياس } & \multirow[b]{2}{*}{ المتغيرات } \\
\hline (ES) & $\left(n^{2}\right)$ & & 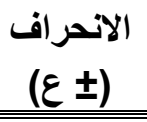 & 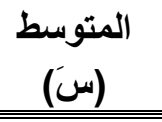 & 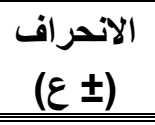 & $\begin{array}{c}\text { المتوسط) } \\
\text { (س) }\end{array}$ & & \\
\hline 1.8 & 0.791 & 5.84 & 1.29 & 69.90 & 2.37 & 73.60 & نبضة/دقيقة & معدل النبض \\
\hline 2.5 & 0.728 & 4.90 & 1.34 & 119.30 & 1.96 & 123.40 & مم/زئبقي & ضغط انقباضي \\
\hline 3.6 & 0.903 & 9.16 & 1.43 & 77.50 & 1.48 & 82.80 & مم/زئبقي & ضغط انبساطي \\
\hline 1.7 & 0.586 & 3.57 & 7.26 & 48.74 & 18.22 & 71.72 & $\mathrm{mg} \%$ & لاكتيك \\
\hline 1.4 & 0.743 & 5.09 & 0.63 & 3.90 & 0.50 & 3.08 & لتز & IVC \\
\hline 1.6 & 0.756 & 5.28 & 0.74 & 3.73 & 0.77 & 2.50 & لتر & FVC \\
\hline 1.6 & 0.635 & 3.96 & 1.06 & 3.90 & 0.53 & 2.53 & لتز & FEV1 \\
\hline 1.3 & 0.725 & 4.87 & 1.06 & 100.30 & 2.82 & 96.80 & $\%$ & FEV1/FVC \\
\hline 1.9 & 0.792 & 5.86 & 7.29 & 89.90 & 7.46 & 76.10 & $\%$ & FEV1/VC \\
\hline 2.0 & 0.685 & 4.43 & 1.32 & 7.02 & 0.64 & 4.94 & لتز & PEF \\
\hline 3.1 & 0.796 & 5.92 & 1.02 & 7.18 & 0.97 & 4.14 & لتر/ثانية & MEF75 \\
\hline 1.6 & 0.714 & 4.74 & 1.19 & 5.75 & 0.72 & 4.11 & لتر/ثانية & MAF50 \\
\hline 1.5 & 0.758 & 5.31 & 1.28 & 4.43 & 0.76 & 2.71 & لتر/ثانية & MAF25 \\
\hline 1.2 & 0.767 & 5.44 & 0.04 & 3.91 & 0.03 & 3.87 & لتر/ دقيقة & الاستهلاك الأقصى \\
\hline
\end{tabular}

$$
\text { تج }
$$

يتضـح من الجدول السابق أن قيم (ت) المحسوبة تزاوحت بين (3.57) و (9.16). ولتحديد

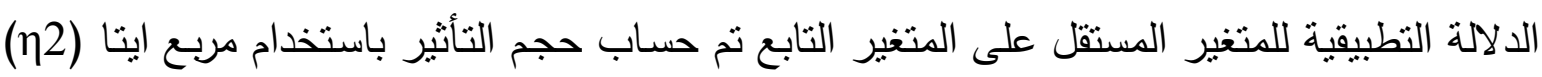

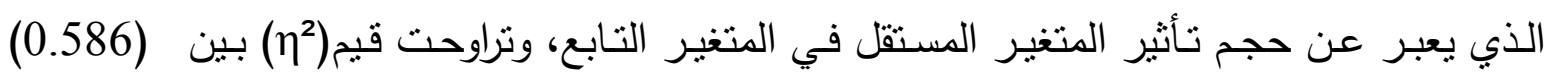
و (0.903) وهذا يدل على حجم تأثير (ضخم Huge). وتراوحت قيم(ES) بين (1.2) و (3.6) وهذا يدل على حجم تأثير (كبير جدا Very Large) إلى (ضخم Huge). جدول (6) 
نسبة التحسن بين درجات (المجموعة التجريبية) في المتغيرات قيد البحث. (ن=10)

\begin{tabular}{|c|c|c|c|c|c|}
\hline التحسبة & القرق بين & القياس البعدي & القياس القبلي & وحدة القياس & المتغيرات \\
\hline 5.03 & 3.70 & 69.90 & 73.60 & نبضة/دقيقة & معدل النبض \\
\hline 3.32 & 4.10 & 119.30 & 123.40 & مم/زئبقي & ضغط انقباضي \\
\hline 6.40 & 5.30 & 77.50 & 82.80 & مم/زئبقي & ضغط انبساطي \\
\hline 32.04 & 22.98 & 48.74 & 71.72 & $\mathrm{mg} \%$ & لاكتيك \\
\hline 26.93 & 0.83 & 3.90 & 3.08 & لتر & IVC \\
\hline 49.26 & 1.23 & 3.73 & 2.50 & لتر & FVC \\
\hline 54.20 & 1.37 & 3.90 & 2.53 & لتز & FEV1 \\
\hline 3.62 & 3.50 & 100.30 & 96.80 & $\%$ & FEV1/FVC \\
\hline 18.13 & 13.80 & 89.90 & 76.10 & $\%$ & FEV1/VC \\
\hline 42.24 & 2.09 & 7.02 & 4.94 & لتر & PEF \\
\hline 73.71 & 3.05 & 7.18 & 4.14 & لتر/ثانية & MEF75 \\
\hline 39.89 & 1.64 & 5.75 & 4.11 & لتر/ثانية & MAF50 \\
\hline 63.31 & 1.72 & 4.43 & 2.71 & لتر/ثانية & MAF25 \\
\hline 1.09 & 0.04 & 3.91 & 3.87 & لتر/ دقيقة & الحد الأقصى لاستهلاك \\
\hline
\end{tabular}

يتضح من الجدول السابق أن قيم (نسبة التحسن) تراوحت بين (1.09) و (73.71).

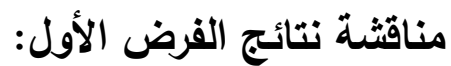

يتضـح من جدول (5)، (6)، وجود فروق داله إحصـائيا بين القياس القبلي والقياس البعدي

للمجموعة التجريبية في متغيرات اللياقة القلبية التنفسية، حيث تحسن معدل النبض بنسبة 5.03 كما تحسن ضـغط اللـم الانبسـاطي بنسبة 3.32، وتحسن ضـطط الـدم الانقباضـي بنسبة 6.40، ويـرى الباحثون ان هذه النتيجة ترجع الى استخدام تمرينات البيلاتس نظرا لأنها تعمل على تحسين لياقة القلب والتنفس مما يخفض من عدد ضربات القلب أثناء الراحة نتيجة لزيادة حجم عضلة القلب وزيادة ضخ الدم للجسم. وهذا يتفق مع ما أنتار إليه كلا من كارون كارتز (2001)، كاثى ميبوبس، سالي سيرل (2006) أن تمارين البيلاتس تعمل على استرخاء العضلات وتهيئتها بعد المجهود العضلي وبالتالي تعمل على خفض النبض والاقلال من معدل ضـربات القلب والحمايـة من امراض القلب والارتفاع

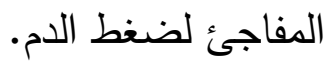

كما نظهر النتائج أيضا تحسن نسبة حامض اللاكتيك 32.04 كما يتضح ايضـا تحسن الحد الأقصى لاسـتهلاك الأكسـجين بنسبة 1.09 حيث يرجـع البـاحثون هذا التحسـن الى أداء تمرينـات 
البيلاتس وذلك لاعتمادها بالأساس على التنفس الطويل والبطيء والعميق والذي يساعد على امتلاء الرئة بالأكسجين وزيادة نسبة الأكسجين بالدم والعضلات مما يساعد علي التخلص من مخلفات الجهد

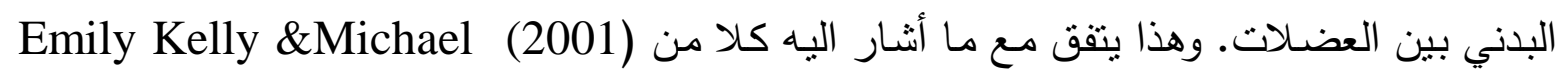
King، دوناتلو (2005)، محمد احتشـام (2012)، ان تمرينات البيلاتس تعمل على تحسين عملية التنفس وتقويـة العضـلات بين الضلوع والحجاب الحاجز وتطهير الجسم من الفضـلات مثل حامض كل اللاكتيك وثاني أكسيد الكربون، كما انه من خلال التتفس العميق يحدث زيادة في كمية الأكسجين التي يتم استتشاقها وتوزيعها على أنسجة الجسم وبالتالي تحسن وظائف الرئة والقلب. وتتفق هذه النتيجة مـع نتائج دراسـة كـلا من عاليـة شـس الــين (2009)، ايمسان عسكر (2011)، نسمة فراج (2012)، مدحت قاسم (2015)، الحسيني محمد (2017)، محمود عبد الله (2020). حيث أنثتت هذه الدراسات تأثير تمرينات البيلاتس على اللياقة القلبية والتتفسية وحمض اللاكتيك، مما يثبت صحة الفرض الأول والذي ينص على " توجد فروق ذات دلالة إحصائية بين

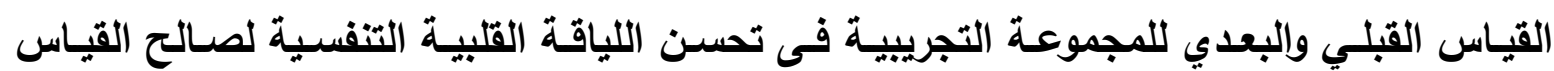

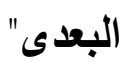

\section{عرض ومناقثة نتائج الفرض الثاني: عرض نتائج الفرض الثاني:}

ينص الفرض الثاني على أنه :"توجد فروق ذات دلالـة إحصـائية فى القياس البعدي بين المجموعة التجريبيـة والضـابطة فى تحسن اللياقة القلبيـة التنفسية لصـالح المجموعة التجريبية"؛ وللتحقق مـن صـحة الفرض الثالث استخدم البـاحثون اختبار (ت) لعينتين مسـتقلتين مـن البيانات

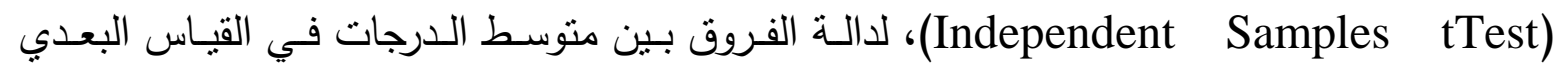
(للمجوعة التجريبية) والقياس البعدي لمجموعة (للمجموعة الضابطة)، في المتغيرات قيد البحث، كما تم حساب حجم التأثير (Effect Size) باستخدام مربع ايتا (2) في حالة اختبار (ت)، كما تم حسـاب حجم التأثثر باستخدام (ES) ويفسر طبقا لمحكات لكوهين، بالإضـافة إلى نسبة التغيير / التحسن (Change Ratio)، كما في الجداول والأشكال التالية. جدول(9)

دلالة الفروق بين القياس البعدي (للمجموعة التجريبية) والقياس البعدي (للمجموعة الضابطة) 
في المتغيرات قيد البحث (ن 1=ن=2010)

\begin{tabular}{|c|c|c|c|c|c|c|c|c|}
\hline \multicolumn{2}{|c|}{ حجم التأثير } & \multirow{2}{*}{ قيمة } & \multicolumn{2}{|c|}{ المجموعة الضابطة } & \multicolumn{2}{|c|}{ المجموعة التجريبية } & \multirow{2}{*}{ القياس } & \multirow[b]{2}{*}{ المتغيرات } \\
\hline (ES) & $\left(\eta^{2}\right)$ & & 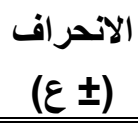 & المتوسط) & 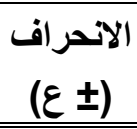 & المتوسط) & & \\
\hline 2.0 & 0.497 & 4.22 & 2.79 & 74.00 & 1.29 & 69.90 & نبضة/دقيقة & معدل النبض \\
\hline 2.0 & 0.508 & 4.31 & 1.84 & 122.40 & 1.34 & 119.30 & مم/زئبقي & ضغط انقباضي \\
\hline 1.9 & 0.486 & 4.12 & 1.90 & 80.60 & 1.43 & 77.50 & مم/زئبقي & ضغط انبساطي \\
\hline 1.3 & 0.290 & 2.71 & 12.32 & 61.00 & 7.26 & 48.74 & mg \% & لاكتيك \\
\hline 1.2 & 0.264 & 2.54 & 0.68 & 3.16 & 0.63 & 3.90 & لتر & IVC \\
\hline 1.4 & 0.330 & 2.98 & 0.53 & 2.87 & 0.74 & 3.73 & لتر & FVC \\
\hline 1.4 & 0.338 & 3.03 & 0.63 & 2.72 & 1.06 & 3.90 & لتر & FEV1 \\
\hline 1.2 & 0.274 & 2.60 & 12.46 & 90.00 & 1.06 & 100.30 & $\%$ & FEV1/FVC \\
\hline 1.2 & 0.262 & 2.53 & 26.27 & 68.10 & 7.29 & 89.90 & $\%$ & FEV1/VC \\
\hline 1.5 & 0.350 & 3.11 & 1.47 & 5.08 & 1.32 & 7.02 & لتر & PEF \\
\hline 2.2 & 0.538 & 4.58 & 1.55 & 4.50 & 1.02 & 7.18 & لتر/ثانية & MEF75 \\
\hline 1.4 & 0.339 & 3.04 & 1.43 & 3.96 & 1.19 & 5.75 & لتر/ثانية & MAF50 \\
\hline 1.7 & 0.408 & 3.52 & 1.09 & 2.56 & 1.28 & 4.43 & لتر/ثانية & MAF25 \\
\hline 1.3 & 0.307 & 2.82 & 0.02 & 3.87 & 0.04 & 3.91 & لتر/ دقيقة & $\begin{array}{l}\text { الأكسجين الأقصى لاستهلاك (vo } \\
\text { (vormax }\end{array}$ \\
\hline
\end{tabular}

تج (18) $2.10=0.05$

يتضـح من الجدول السـابق أن قيم (ت) الدحسوبة تراوحت بين (2.53) و (4.58). ولتحديد

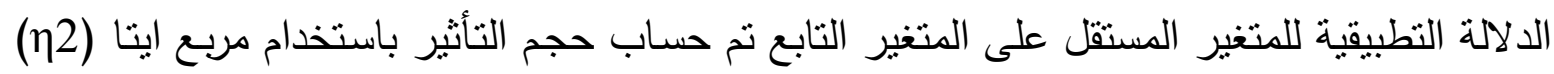

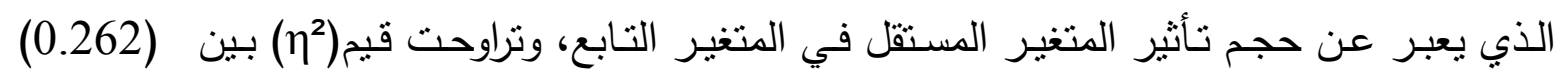

و (0.538) وهذا يدل على حجم تأثير (كبير جدا Very Large) إلى (ضخم (Huge). وتراوحت قيم(ES) بين (1.2) و (2.2) وهذا يدل على حجم تأثير (كبير جدا Very Large) إلى (ضخم

.(Huge

جدول (10)

الفروق في نسبة التحسن بين (المجموعة التجريبية)، و (المجموعة الضابطة)

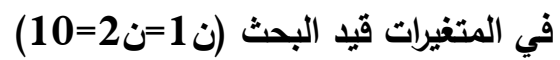

\begin{tabular}{|c|c|c|c|c|c|c|c|}
\hline \multicolumn{2}{|c|}{ الفروق بين القياسات } & \multicolumn{2}{|c|}{ المجموعة الضابطة } & \multicolumn{2}{|c|}{ المجموعة التجريبية } & \multirow[b]{2}{*}{ وحدة القياس } & \multirow[b]{2}{*}{ المتغيرات } \\
\hline في نسبة & في متوسط القياسين & نسبة & القتباس البعدي & نسبة & القتباس البعدي & & \\
\hline
\end{tabular}




\begin{tabular}{|c|c|c|c|c|c|c|c|}
\hline 3.70 & 4.10 & 1.33 & 74.00 & 5.03 & 69.90 & نبضة/دقيقة & معدل النبض \\
\hline 3.07 & 3.10 & 0.25 & 122.40 & 3.32 & 119.30 & مم/زئبقي & ضغط انقباضي \\
\hline 3.98 & 3.10 & 2.42 & 80.60 & 6.40 & 77.50 & مم/زئبقي & ضغط انبساطي \\
\hline 27.22 & 12.26 & 4.82 & 61.00 & 32.04 & 48.74 & $\mathrm{mg} \%$ & لاكتيك \\
\hline 22.64 & 0.74 & 4.29 & 3.16 & 26.93 & 3.90 & لتر & IVC \\
\hline 38.44 & 0.86 & 10.82 & 2.87 & 49.26 & 3.73 & لتر & FVC \\
\hline 40.74 & 1.18 & 13.46 & 2.72 & 54.20 & 3.90 & لتز & FEV1 \\
\hline 1.34 & 10.30 & 2.28 & 90.00 & 3.62 & 100.30 & $\%$ & FEV1/FVC \\
\hline 5.66 & 21.80 & 12.47 & 68.10 & 18.13 & 89.90 & $\%$ & FEV1/VC \\
\hline 24.22 & 1.94 & 18.02 & 5.08 & 42.24 & 7.02 & لتر & PEF \\
\hline 56.40 & 2.68 & 17.31 & 4.50 & 73.71 & 7.18 & لتر/ثانية & MEF75 \\
\hline 29.20 & 1.79 & 10.69 & 3.96 & 39.89 & 5.75 & لتر/ثانية & MAF50 \\
\hline 40.81 & 1.87 & 22.50 & 2.56 & 63.31 & 4.43 & لتر/ثانية & MAF25 \\
\hline 0.73 & 0.04 & 0.36 & 3.87 & 1.09 & 3.91 & لتر/ دقيقة & الاستهلالكى الأقصى \\
\hline
\end{tabular}

يتضح من الجدول السابق أن الفروق في نسبة التحسن تزاوحت بين(0.73) و (56.4).

مناقشة نتائج الفرض الثاني:

يتضـح مـن جدول (9)، (10)، وجـود فروق ذات دلالـة إحصـائية في القيـاس البعدي بين

الهجموعة التجريبية والضابطة في تحسن اللياقة القلبية التنفسية لصالح الهجموعة التجريبية.

حيث تظهر النتائج تحسن معدل النبض في المجموعـة التجريبيـة بنسبة 5.03، بينمـا في

المجموعـة الضـابطة بنسبة 1.33، كمـا تحسـن قيمـة الضـغط الانقباضـي بنسبة 3.32، بينمـا في

المجموعة الضـابطة 0.25، كمـا تحسن قيمـة الضغط الانبساطي بنسبة 6.40، بينما في المجموعة

الضـابطة بنسبة 2.42. كما تحسن حمض اللاكتيك في المجموعـة التجريبيـة بنسبة 32.04، بينمـا

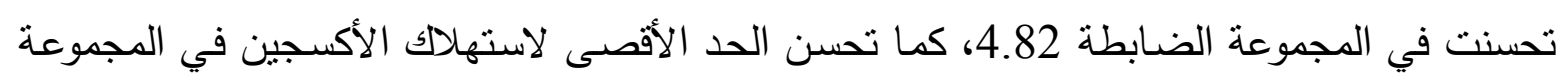
التجريبية بنسبة 1.09، بينما تحسنت في المجموعة الضابطة بنسبة 0.36، ويرى الباحثون ان التحسن في القياس البعدي للمجموعة التجريبية الى استخدام تمرينات البيلاتس لدورها في تحسين اللياقة القلبية التتفسية.

وتتفق تلك النتيجـة مـع مـا أثنار اليه إبراهيم سـلامة 2000م إلى أن التدريب القلبي التتفسي يؤدى إلى إكساب الرياضي ما يعرف بالتكيف الوظيفي للأجهزة الحيوية كنتيجة لهذا التدريب، كما يؤكد 
على أن هناك بعض المتغيرات التي يشير التحسن الملحوظ بها إلى ارتفاع اللياقة القلبية التتفسية ومن

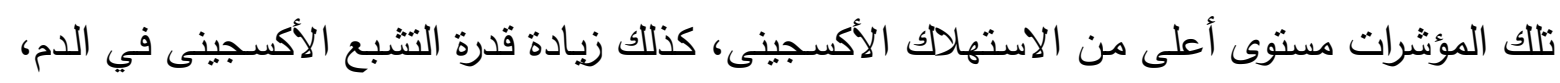

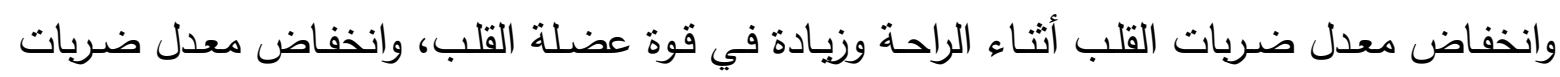
القلب عند مستوى محدد لحمل التدريب، زيادة مستوى العمل الوظيفي، سرعة العودة لحالة الثفاء، كما تتفق تلك النتيجة مـع ما أنشار اليه كلا من دونـاتلو (2005)، محمد احتثـام (2012)، ان تمرينات البيلاتس تعمل على تطهير الجسم من الفضلات متل حامض اللاكتيك وثاني أكسيد الكربون. وتتفق هذه النتيجة مـع نتائج دراسـة كـلا من عاليـة شـس الـدين (2009)، ايمسان عسكر (2011)، نسمة فراج (2012)، مدحت قاسم (2015)، الحسيني محمد (2017)، محمود عبد الله (2020). حيث أثنتت هذه الدراسات تأثثر تمرينات البيلاتس على اللياقة القلبية والتتفسية.

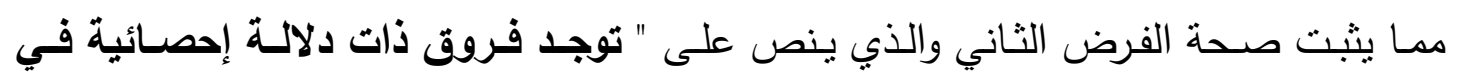

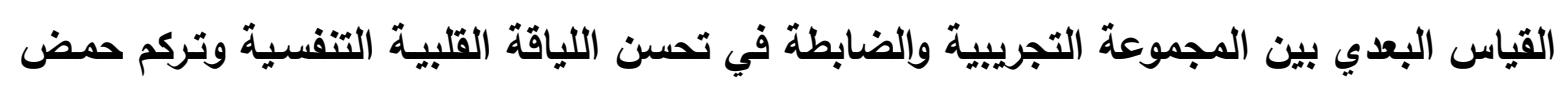
اللاكتيك لصالح المجموعة التجريبية".

\section{الاستنتاجات والتوصيات}

الاستنتاجات:

في ضـوء أهداف البحث وفروضـه وفى حدود عينـة البحث وخصائصـها والمنهج المستخدم والاختبارات والقياسـات المطبقة واعتمـاداً على نتائج الأسلوب الإحصـائي المستخدم أمكن للبـاحثون

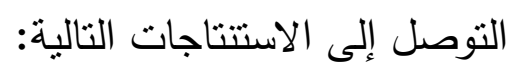

1. أدت تمرينات البيلاتس إلي تحسن معدلات التتفس والسعة الحيوية والسعة الحيوية القسرية. 2. أدت تمرينات البيلاتس إلي تحسن الحد الأقصى لاستهلاك الاكسجين لدى الناعبين. 3. أدت تمرينات البيلاتس الي انخفاض معدل نبض القلب في وقت الراحة لدي اللاعبين. ثانيا : التوصيات: في ضوء النتائج والاستتناجات التي أسفر عنها البحث يوصي الباحثون بما يلي:

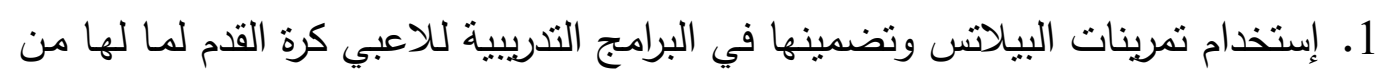
تأثثر في رفع كفاءة الجهاز التتفسي والقلب. 
2. اجراء المزيد من الأبحاث حول تأثير تمرينات البيلاتس على النواحي الفسيولوجية

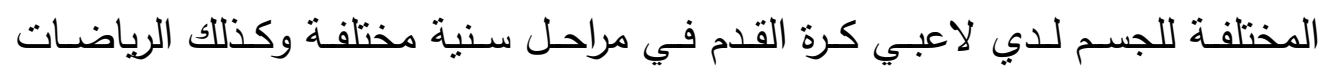
الجماعبة الأخري.

قائمة المراجع

أولا: المراجع العربية :

: التدريب الرياضي والأسسس الفسيولوجية، دار الفكر

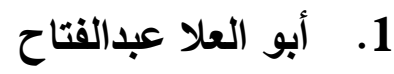

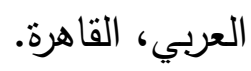

(1997)

: فيولوجيا اللياقة البدنية، دار الفكر العربي، القاهرة،

2. - أبو العلا عبدالفتاح، أحمد

نصرالدين (2003م)

: اللياقـة الطريـق للحيـاة الصـحية، منشــأة المعـارف،

3. إلين وديع فرج (1999م)

$$
\text { الإسكندرية. }
$$

4. ايمان عسكر أحمد (2011م) : تأثثر تدريبات البيلاتس على بعض كتيكولامسنات

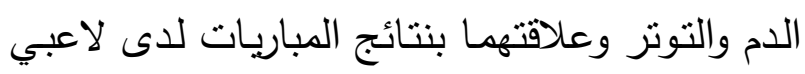

رياضـة الجودو، رسالة دكتوراه، غير منشورة، بكلية

التربية الرياضية جامعة الزقازيق.

: تأثثر برنـامج مقترح للرقص الهوائي على حموضـة

5

المعدة ونشـاط إنزيم الببسين، رسـالة دكتوراه، كلية

(1993)

التربية الرياضية للبنات، جامعة الزقازيق.

: الرياضة ومبادئ البيولوجي، القاهرة.

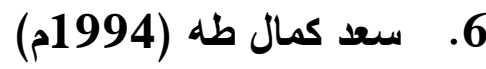

: فاعلية برنامج لتدريبات البيلاتس على اللياقة القليية

7. - عالية عادل شمس الدين

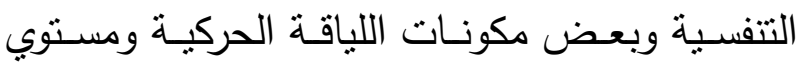

(2009)

الاداء في الـرقص الحديث، رسـالة دكتوراه، غيـر

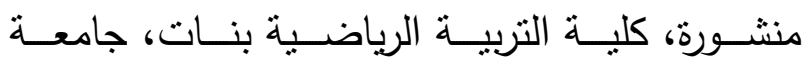

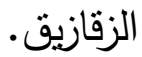

8. عصام عبد الخالق (2005م) التدريب الرياضي (نظريات - تطبيقات)، ط13، دار

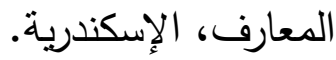


طرق قياس الجهـ البدني فى الرياضة، مركز الكتاب

9 - 9. محمد نصر الدين رضوان

$$
\text { للنشر ، القاهرة. }
$$

(1998)

10. مدحت محمد قاسم (2015م) : تـأثنر اسـتخدام نـوعين مـن التمرينـات "البيلاتس -

الحرة" على بعض المتغيرات الفسيولوجية والبدنيـة

لتلاميذ المرحلة الإعدادية، بحث منشور، كلية التربية

الرياضية، جامعة المنصورة.

11. نسمة محمد فراج (2012م) أثثر استخدام بعض تمرينات البيلاتس على مكونات

اللياقة البدنية المرتبطة بالصحة لطالبات كلية التربية

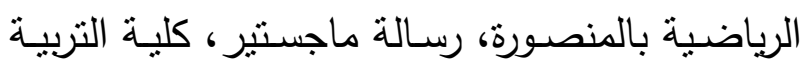

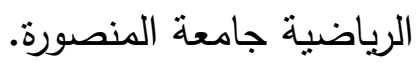

12. نعمات أحمد عبد الرحمن الأنشطة الهوائية، منشأة المعارف، الإسكندرية.

(2000)

ثانيا : المراجع الأجنبية

13. Lange, Claudia, : "Maximizing the benefits of Pilateset al (2000) inspired exercise for learning functional motor skills." Journal of bodywork and Movement Therapies 4.2: 99-108.

14. Austin, Denise : Pilates for Every Body: Strengthen, (2003) Lengthen, and Tone--with this Complete 3week Body Makeover. Rodale.

15. Sekendiz, B., : Effects of Pilates exercise on trunk Altun, Ö., strength, endurance and flexibility in Korkusuz, F., \& sedentary adult females. Journal of Akın, S. (2007) bodywork and movement therapies, 11(4), 318-326.

16. Culligan, : "A randomized clinical trial comparing Patrick J., et al pelvic floor muscle training to a Pilates (2010) exercise program for improving pelvic muscle strength." International urogynecology journal 21.4: 401-408.

17. Rogers, Kate, : "Eight-week traditional mat Pilates 
and Ann L. training-program effects on adult fitness Gibson (2009) characteristics." Research quarterly for exercise and sport 80.3: 569-574.

18. Culligan, : "A randomized clinical trial comparing Patrick J., et al pelvic floor muscle training to a Pilates (2010) exercise program for improving pelvic muscle strength." International urogynecology journal 21.4: 401-408.

19. Karter, Karon : "The complete idiot's guide to the Pilates (2001) method/by Karon Karter.".

20. Hutchinson, "Improving leaping ability in elite MARK R., et al rhythmic gymnasts." Medicine and science (1998) in sports and exercise 30: 1543-1547.

ثالثا: الثبكة الدولية للمعلومات

21. Http://images.lafemmebonita.com/c/w104738.pug

22. Http://pilates.about.com

23. Http://www.pilates.com/bbapp/v/about/pilatesbenefits.html

24. Http://www.pilatesmethoddalliance.org/whatis.html 


\section{ملخص البحث}

يهدف هذا البحث إلي التعرف علي تأثثر تمرينات البيلاتس علي بعض المتغيرات الفسيولوجية

لدي لاعبي كرة القدم تحت 16 سنة، حيث استخدم الباحثون المنهج التجريبي ذو التصميم التجريبي لمجموعنان إحداهما ضابطة والأخري تجريبية لملائمته لطبيعة البحث على عينة قوامها (20) لاعب وكانت أهم النتائج وجود تحسن في كفاء الجهاز التتفسي والقلب كذلك سرعة إستعادة الثفاء نظرا لإنخفاض نسبة حامض اللاكتيك في الدم عقب آداء التدريبات وكانت أهم التوصيات استخدام تمرينات البيلاتس في رفع الكفاءة القلبية التنفسية وكذلك كفاءة باقي أجزة الجسم المختلفة وإستعادة الثفاء.

\section{Abstract}

This research aims to identify the effect of Pilates exercises on some physiological variables of soccer players under 16 years of age, as the researcher used the experimental method with an experimental design for two groups, one of them is control and the other is experimental for its suitability to the nature of the research on a sample of (20) players and the most important results were an improvement in The efficiency of the respiratory system and the heart as well as the speed of recovery of healing due to the decrease in the level of lactic acid in the blood after performing the exercises and the most important recommendations were the use of Pilates exercises in raising the cardiorespiratory efficiency as well as the efficiency of the rest of the various body systems and restoring healing. 